\title{
Effect of 4-biphenyl groups on the charge transport and photovoltaic properties of arylamine based push-pull systems
}

Pablo Simón Marqués, ${ }^{1 \dagger}$ José María Andrés Castán, ${ }^{1 \dagger}$ Pierre Josse,,${ }^{1}$ Martin Blais, ${ }^{1}$ Amir Hossein Habibi, ${ }^{1}$ Ivan Ramirez, ${ }^{2}$ Karsten Walzer, ${ }^{2}$ Jean Roncali, ${ }^{1,3}$ Philippe Blanchard ${ }^{1 *}$ and Clément Cabanetos ${ }^{1^{*}}$

\footnotetext{
${ }^{1}$ CNRS UMR 6200, MOLTECH-Anjou, University of Angers, 2 Bd Lavoisier, 49045 Angers, France

${ }^{2}$ HELIATEK GmbH, Treidlerstraße 3, 01139 Dresden, Germany

${ }^{3}$ Babes-Bolyai University, Faculty of Chemistry and Chemical Engineering, Department of Chemistry and SOOMCC, Cluj-Napoca, 11 Arany Janos Str., 400028, Cluj-Napoca, Romania

${ }^{\dagger}$ Both authors equally contributed to this work
}

\begin{abstract}
Two push-pull derivatives based on a $N, N$-bis(4-biphenylyl)aniline (BPA) donor block connected to a dicyanovinyl accepting moiety by thienyl and bithienyl $\pi$ conjugated spacers have been synthesized and characterized. All-small-molecule planarheterojunction organic solar cells show promising power conversion efficiencies and impressive fill factor ( $>73 \%$ ) correlated with the high hole-mobility induced by the BPA moiety.
\end{abstract}

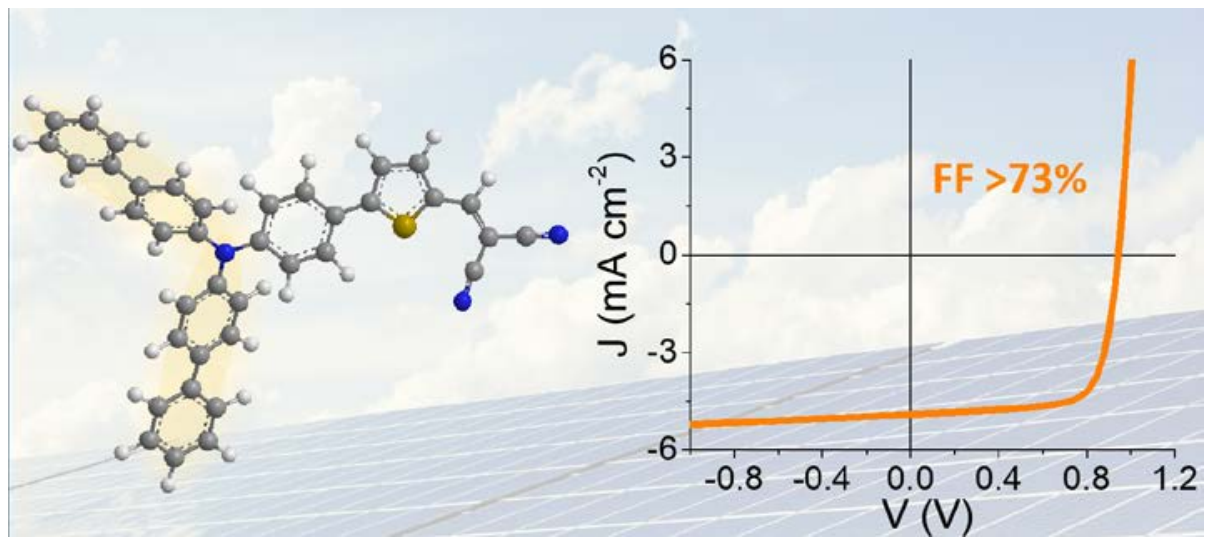

Introduction: Triarylamine derivatives (TAAs) represent a major class of building blocks for the synthesis of hole-transporting materials (HTMs) used in various optoelectronic applications such as organic light-emitting diodes (OLEDs), ${ }^{1}$ organic $^{2}$ and hybrid ${ }^{3}$ solar cells or even in dye-sensitized solar cells (DSSCs). ${ }^{4-7}$ During the past decade, the chemistry of active materials embedded in organic solar cells (OSCs) has witnessed an increasing interest, particularly for the preparation of molecular electron- 
donor materials since they present several advantages compared to macromolecular systems. ${ }^{4,-10}$ Among others, a better reproducibility of the synthesis, purification and properties, a more reliable analysis of the structure-properties relationships and, usually, lower synthetic complexity indexes stand out.

In this context, taking advantage of the strong electron-donating properties and high holemobility of TAA derivatives, active materials based on push-pull compounds have attracted considerable attention in organic photovoltaics (OPVs). ${ }^{41-13,2}$ Thus, in these recent years, various classes of molecular donors that include TAA units have been developed resulting in the preparation of star-shaped architectures, ${ }^{14}, 15$ D-A-D compounds $^{16,17}$ and simple D-A systems. ${ }^{18-20}$ As shown in a recent work, when implemented in optimized vacuum-deposited OSCs, small push-pull molecules can lead to power conversion efficiencies (PCE) exceeding $10 \% .{ }^{13}$ Although these values are still lower than those recorded with polymer-based bulk-heterojunction cells (ca 18\%), ${ }^{6}$ it should be underlined that these performances are usually obtained with active compounds of considerably simpler chemical structures. ${ }^{4,21}$

In our continuing interest for active materials based on simple and accessible structures, we have undertaken a systematic analysis of the structure-properties relationships induced by subtle modifications on a reference compound comprised of a triphenylamine (TPA) donor block, connected to a dicyanovinyl acceptor unit through a $\pi$-conjugating spacer (TPA-T-DCV), ${ }^{18}$ which structure is illustrated in Figure 1.
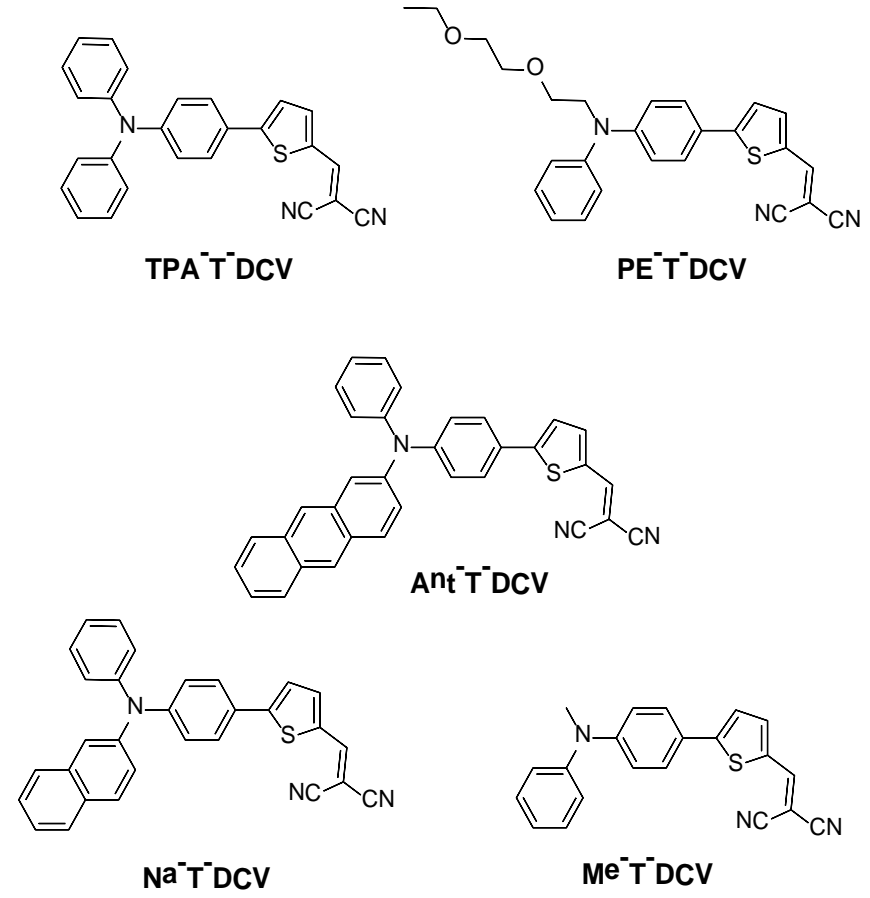

Figure 1. Structure of push-pull-based molecular donors studied in the group. 
Over the years, our group has shown that the structural manipulation of the TAA block can exert a considerable impact on the properties of the resulting material with little or no influence on the electronic properties of the molecule. For instance, while the replacement of one phenyl ring of the TPA by a polyether chain leads to the emergence of unsual and unexpected mechano-fluoro-NLO-chromic properties (PE-T-DCV), ${ }^{22}$ the same substitution by an anthryl (Ant-T-DCV), ${ }^{23}$ a naphthyl (Na-T-DCV) ${ }^{24}$ or even a simple methyl group (Me-T-DCV) ${ }^{25}$ results in a three-, five- and fifty- fold increase of the hole mobility, respectively.

In the context of improving the charge transport properties, the substitution of the outer phenyl rings of TPA by biphenyl (BP) blocks has proven effective for the synthesis of efficient HTMs. ${ }^{26-28}$ On this basis, we report herein the synthesis, characterization and early evaluation in bilayer OSCs of two push-pull molecular donors, namely BPA-TDCV and BPA-BT-DCV (Figure2), with mono- (T) or bithienyl (BT) $\pi$-conjugated spacers respectively in which the TPA is replaced by $N, N$-bis(4-biphenylyl)aniline (BPA).
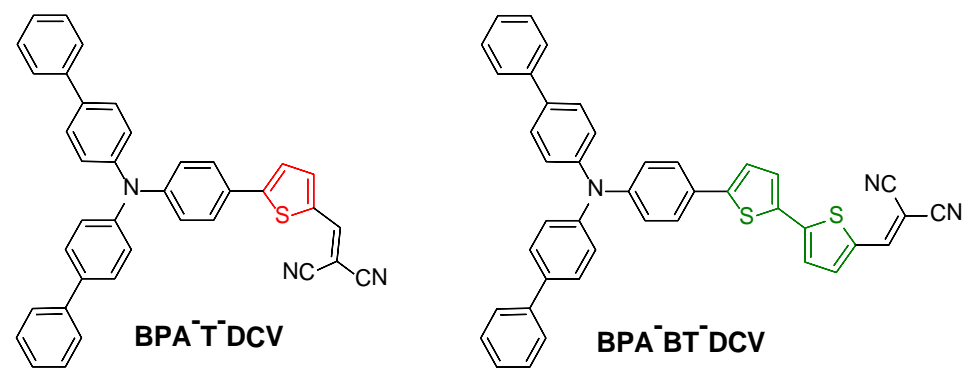

Figure 2. Chemical structure of the target push-pull molecules.

Results and discussion: The synthetic route considered herein for the preparation of both target push-pull derivatives, in only two steps, is depicted in Scheme 1. 


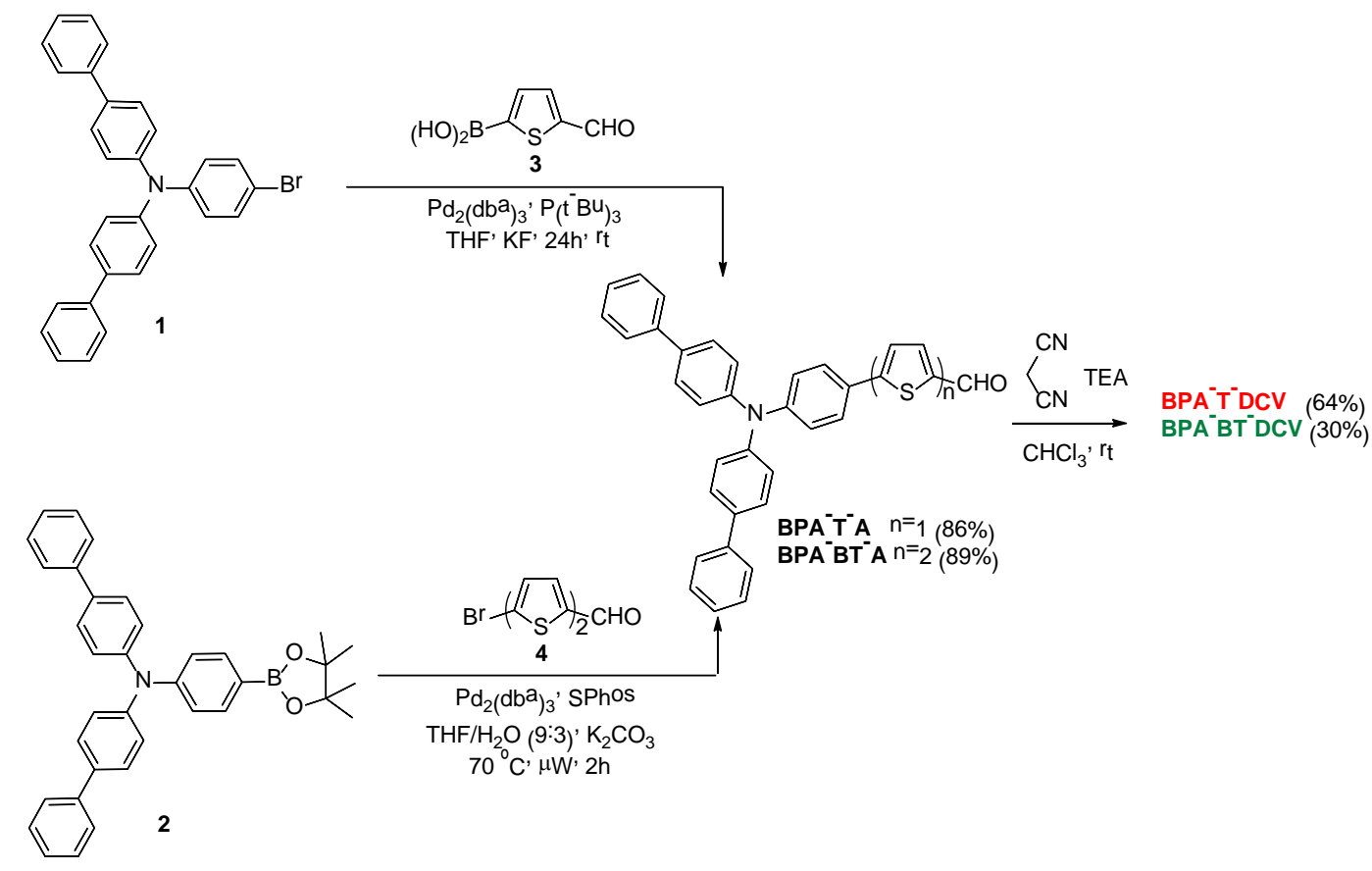

Scheme 1. Synthesis of the target compounds, namely BPA-T-DCV and BPA-BT-DCV.

First, the $N, N$-bis(4-phenylyl)- $N$-(4-bromophenyl)amine 1 and its boronic acid pinacol ester analogue 2 were engaged in Suzuki-Miyaura cross coupling reactions with (5formylthiophen-2-yl)boronic acid $\mathbf{3}$ and 5-bromothiophene-2-carbaldehyde $\mathbf{4}$ respectively, under mild conditions, ${ }^{29,} 30$ to afford in good yields the corresponding aldehyde derivatives, namely BPA-T-A and BPA-BT-A. Hence, the latter were finally converted into the target compounds by reaction with malononitrile under base-catalyzed Knoevenagel condensation conditions. While both push-pull derivatives show good solubility in common organic solvents, modest synthetic yields were obtained - mainly due to the meticulous purification procedure consisting of a column chromatography followed by injection in a recycling size-exclusion HPLC and finally a recrystallization. Once characterized by nuclear magnetic resonance spectroscopy and high resolution mass spectrometry, the optical properties of BPA-T-DCV and its bithienyl analogue (BPABT-DCV) were investigated (Figure 3). 
a)

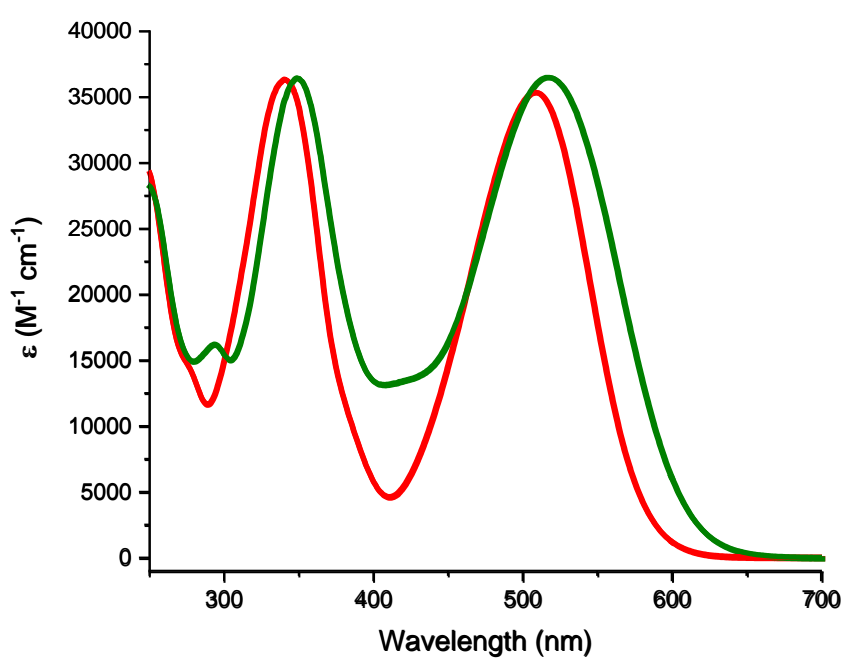

b)

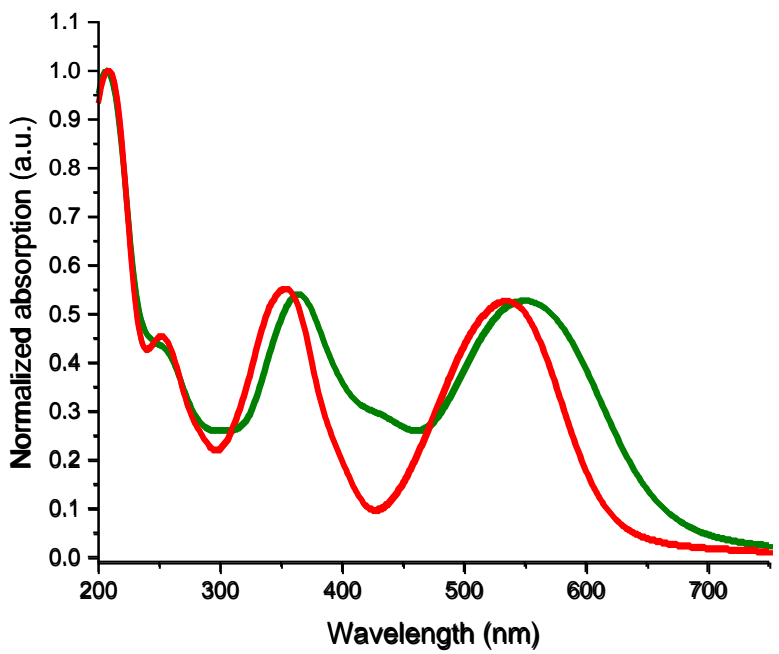

Figure 3. UV-Vis absorption spectra of BPA-T-DCV (red) and BPA-BT-DCV (green) in dichloromethane (a) and as evaporated thin films on quartz (b).

Solubilized in dichloromethane (DCM), both compounds show a UV-Vis absorption spectrum exhibiting a first band with a maximum at $c a 350 \mathrm{~nm}$ assigned to the $\pi-\pi^{*}$ transition of the BPA-connector block, followed by a broad band in the 400-600 nm region attributed to an intramolecular charge transfer (ICT) from the electron-rich BPA block to the dicyanovinyl (DCV) acceptor moiety. Comparison of both spectra revealed that lengthening the $\pi$-conjugating spacer, from one to two thiophenes, induced a bathochromic shift of $c a 8 \mathrm{~nm}$ and a broadening of the ICT band of $c a 40 \mathrm{~nm}$. Moreover, this structural extension also induces an increase in the absorbance in the 370-430 nm region reflecting a higher contribution of the oligothiophene segment.

As generally observed for $\pi$-conjugated systems, the spectra in thin films present a broadening of the absorption band and a red-shift of the maxima due to intermolecular interactions in the solid state. Compared to solution spectra, the larger red-shift of the absorption maxima observed for BPA-BT-DCV suggests a planarization of the bithiophene spacer due to the molecular packing in the film.

Thereafter, the electrochemical properties of both push-pull molecules have been analyzed by cyclic voltammetry in a solution of tetrabutylammonium hexafluorophosphate $\left(\mathrm{Bu}_{4} \mathrm{NPF}_{6}\right)$, used as the supporting electrolyte, in DCM (Figure 4). 


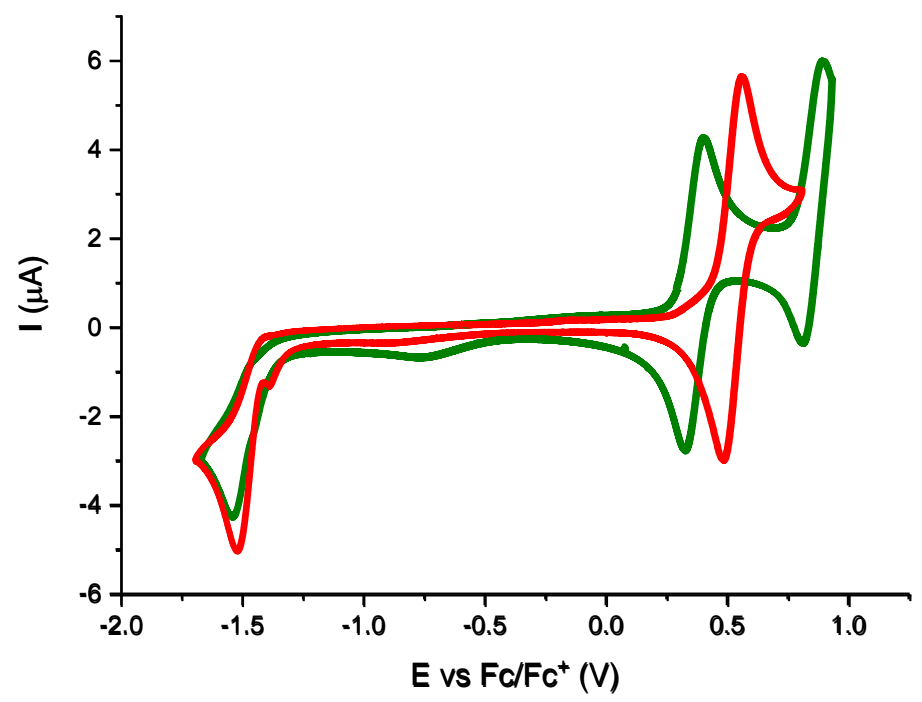

Figure 4. Cyclic voltammograms (CV) of BPA-T-DCV (red) and BPA-BT-DCV (green) recorded at a concentration of $0.5 \mathrm{mM}$ in $0.10 \mathrm{M} \mathrm{Bu}_{4} \mathrm{NPF}_{6} / \mathrm{CH}_{2} \mathrm{Cl}_{2}, 100 \mathrm{mV} \mathrm{s}^{-}$ ${ }^{1}$, Pt working electrode.

The cyclic voltammogram (CV) of BPA-T-DCV shows a one-electron reversible oxidation wave with anodic peak potential $\left(E_{\mathrm{pa}}\right)$ at $+0.56 \mathrm{~V}$ corresponding to the formation of a stable radical cation. The CV of its bithienyl counterpart, namely BPA-BT-DCV, exhibits two reversible anodic waves at $E_{\mathrm{pa}}{ }^{1}=+0.46 \mathrm{~V}$ and $E_{\mathrm{pa}}{ }^{2}=+0.95 \mathrm{~V}$ respectively, attributed to the successive formation of a stable radical cation and dication, thus demonstrating the impact of the $\pi$-connector on the ionization potential. On the other hand, the latter seems to have a limited effect on the electronic affinity since both CVs show, in the negative region, an irreversible reduction peak with very close $E_{\mathrm{pc}}$, thus underlining a process that predominantly involves the dicyanovinyl group and its vicinal thienyl moiety. Optical and electrochemical data are gathered in Table 1.

Table 1. Optical and electrochemical data of BPA-T-DCV and BPA-BT-DCV.

\begin{tabular}{|c|c|c|c|c|c|c|c|c|c|}
\hline Compound & $\begin{array}{c}\lambda_{\max }^{\mathrm{a}} \\
{[\mathrm{nm}]}\end{array}$ & $\begin{array}{c}\mathrm{Log} \varepsilon \\
{\left[\mathrm{M}^{-1} \mathrm{~cm}^{-1}\right]}\end{array}$ & $\begin{array}{c}\lambda_{m a x}^{f i l m} \\
{[\mathrm{~nm}]^{\mathrm{b}}}\end{array}$ & $\begin{array}{c}E_{\mathrm{pa}} \\
{[\mathrm{V}]}\end{array}$ & $\begin{array}{c}E_{\mathrm{pc}} \\
{[\mathrm{V}]}\end{array}$ & $\begin{array}{c}E_{\mathrm{HOMO}}{ }^{\mathrm{fig}} \\
{[\mathrm{eV}]}\end{array}$ & $\begin{array}{c}E_{\mathrm{LUMO}}{ }^{\mathrm{Cu}} \\
{[\mathrm{eV}]}\end{array}$ & $\begin{array}{c}\Delta E_{\text {elec }} \\
{[\mathrm{eV}]}\end{array}$ & $\begin{array}{c}E_{\mathrm{g}}{ }^{\mathrm{d}} \\
{[\mathrm{eV}]}\end{array}$ \\
\hline BPA-T-DCV & 340 & 4.56 & 352 & 0.56 & -1.54 & -5.30 & -3.39 & 1.91 & 2.13 \\
& $\mathbf{5 0 9}$ & $\mathbf{4 . 5 5}$ & $\mathbf{5 2 4}$ & & & & & & \\
BPA-BT-DCV & 349 & 4.56 & 359 & 0.46 & -1.52 & -5.22 & -3.50 & 1.72 & 2.06 \\
& $\mathbf{5 1 7}$ & $\mathbf{4 . 5 6}$ & $\mathbf{5 4 3}$ & 0.95 & & & \\
\hline
\end{tabular}

${ }^{\mathrm{a}} \mathrm{In} \mathrm{CH}_{2} \mathrm{Cl}_{2}$ solutions; ${ }^{\mathrm{b}}$ thin films on quartz.; ${ }^{\mathrm{c}}$ estimated from the onset of the oxidation and reduction processes; ${ }^{\mathrm{d}}$ from the absorption onsets of films. 
To further investigate these differences, and more precisely the impact of the $\pi$ connectors on the frontier energy levels, ground-state density-functional theory (DFT) calculations were carried out with Gaussian 09 using Becke's three-parameter gradientcorrected functional (B3LYP) with the 6-311G* basis set (Figure 5).

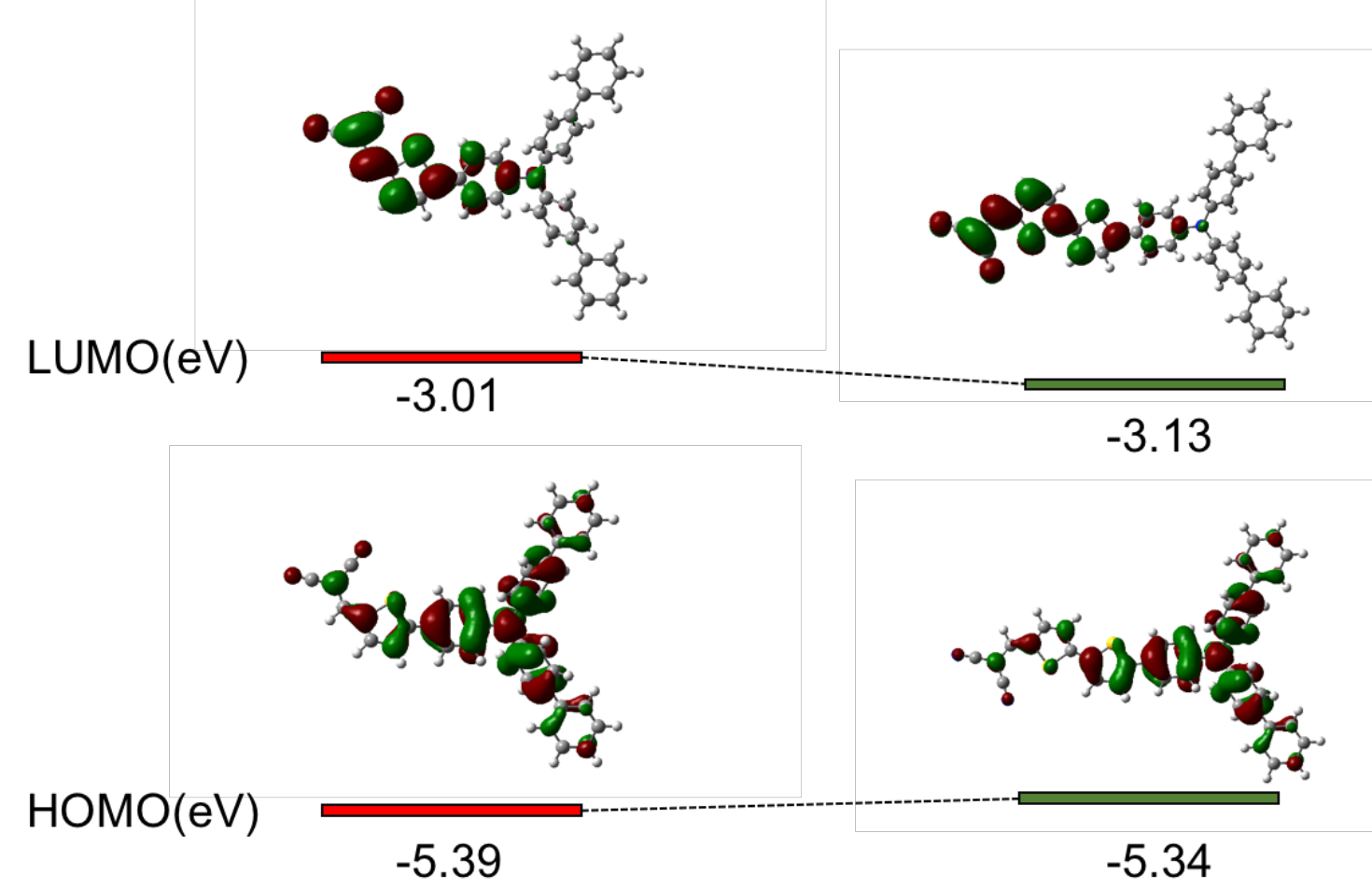

Figure 5. HOMO and LUMO energy levels and their representations for BPA-T-DCV (left) and BPA-BT-DCV (right) after optimization with Gaussian 09 at the B3LYP/ 6$311 G^{*}$ level of theory.

Hence, optimized geometries and computed electronic structures at the observed minima revealed that the HOMO levels are distributed all over the backbone with a major density found on the electron-rich blocks (BPA-connector) while the LUMO levels are mostly localized on the $\pi$-spacer-dicyanovinyl moieties. In addition, calculations showed that lengthening the $\pi$-conjugated thienyl connector reduced the overlapping of the two frontier orbitals resulting in a narrower gap, in accordance with the optical and electrochemical data.

Prior to investigating the photovoltaic performances of these two new molecular donors, evaporation tests under high vacuum $\left(10^{-6} \mathrm{mbar}\right)$ were first carried out. As expected, BPA-T-DCV showed a lower evaporation temperature than its lengthened counterpart 
BPA-BT-DCV, of ca $155^{\circ} \mathrm{C}$ vs $255^{\circ} \mathrm{C}$ respectively, as well as a significantly lower percentage of residue found in the crucible after evaporation (3\% vs $13 \%$ of the mass respectively). Both push-pull derivatives therefore show good evaporability/compatibility with vacuum processing and can be used for the preparation of all-vacuum-processed planar-heterojunction (PHJ) solar cells. Consequently, their photovoltaic properties were investigated via a collaborative effort with the German company Heliatek GmbH through the fabrication and characterization of devices whose architecture is depicted in Figure 6.
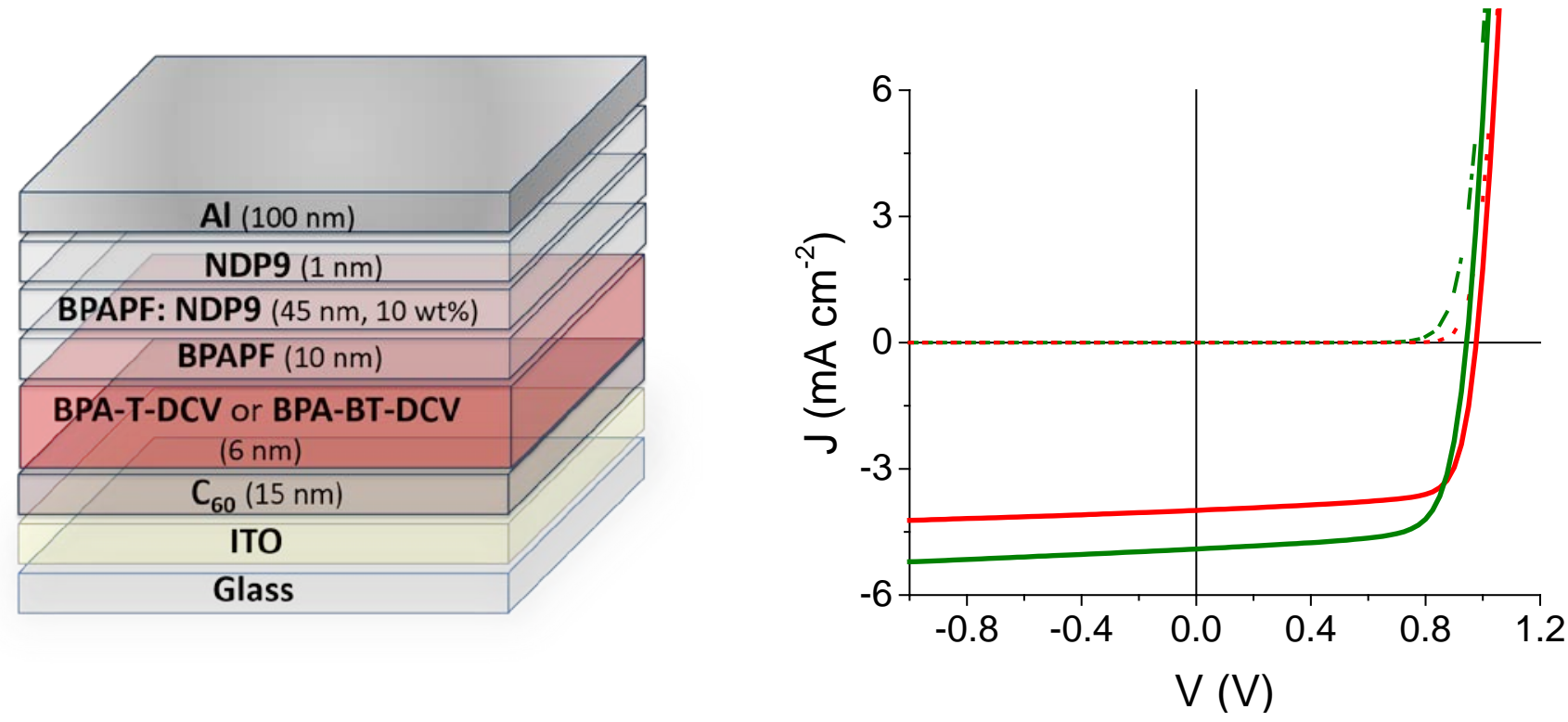

Figure 6. Structure and characteristic J-V curves of both BPA-T-DCV (red) and BPA$\boldsymbol{B T}-\mathbf{D C V}$ (green) derived OSCs recorded in the dark (dashed lines) and under AM 1.5 illumination at $100 \mathrm{~mW} . \mathrm{cm}^{-2}$ (full lines). BPAPF: 9,9-bis[N,N-bis-biphenyl-4-ylamino)phenyl]-9H-fluorene; NDP9: commercial p-dopant from Novaled AG, Dresden.

Comparison of the current density-voltage $(J-V)$ curves first revealed high open-circuit voltages $\left(V_{o c}\right)$ of $0.98 \mathrm{~V}$ and $0.94 \mathrm{~V}$ for BPA-T-DCV and BPA-BT-DCV respectively, consistant with the low-lying HOMO levels of both donors, resulting in a large offset with the LUMO level of the fullerene acceptor. In addition, the slight difference in $V_{o c}$ of $c a$ $40 \mathrm{mV}$, in favor of BPA-T-DCV, is correlated to its deeper HOMO level and higher absorption onset energy. On the other hand, the broader absorbing properties of the bithienyl derivative (BPA-BT-DCV) likely contribute to the $\mathrm{ca} 1 \mathrm{~mA} . \mathrm{cm}^{-2}$ short-circuit current density $\left(J_{s c}\right)$ difference recorded between the two devices since $4.0 \mathrm{~mA} . \mathrm{cm}^{-2}$ were measured for BPA-T-DCV vs 4.9 mA.cm ${ }^{-2}$ for BPA-BT-DCV (Figure S18). Finally, it is noteworthy that impressive fill-factors $(F F)$, above $73 \%$ were reached for both 
molecules (75\% and 73\% for BPA-T-DCV and BPA-BT-DCV respectively). While it is indeed well established that the use of additional hole transporting layers (BPAPF) and extraction/injection barriers (BPAPF doped with NDP9/NDP9) has a beneficial effect on the $F F$, such values, amongst the highest reported so far, ${ }^{19,} 31$ have been barely achieved in all-small molecule OSCs. ${ }^{32-36}$ and contribute to the interesting power conversion efficiencies of 3.0 and 3.3\% obtained with BPA-T-DCV and BPA-BT-DCV respectively in spite of relatively modest $J_{s c}$ values. Consequently, to gain further insight, the charge transport properties of both push-pull derivatives were evaluated through the use of the space-charge limited current (SCLC) method on hole only devices of architecture: ITO/PEDOT:PSS/ BPA-T-DCV or BPA-BT-DCV /Au. From the recorded $J-V$ characteristics, plotted in Figure 7, hole mobilities of ca 1 x $10^{-3} \mathrm{~cm}^{2} \mathrm{~V}^{-1} \mathrm{~s}^{-1}$ were measured for both push-pull derivatives. Interestingly these values are two orders of magnitude higher than the one measured for the reference compound TPA-T-DCV, highlighting the interest of using $\pi$-extended TAA blocks for improving hole transport.

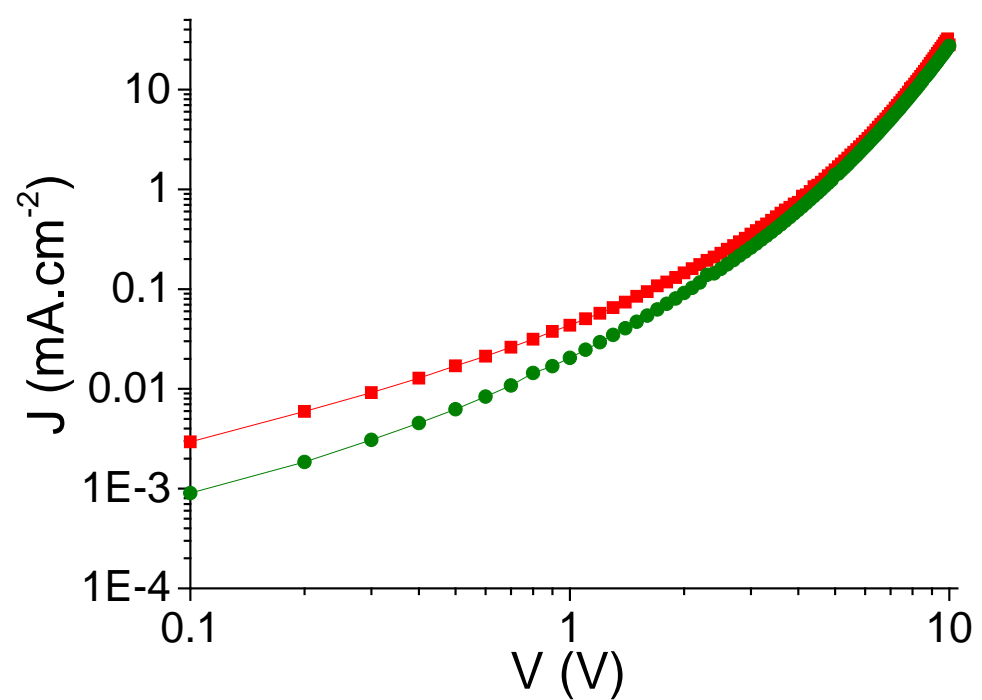

Figure 7. J-V curves recorded from hole only devices of architecture ITO/PEDOT:PSS/ BPA-T-DCV (red) or BPA-BT-DCV (green)/Au.

These values, amongst the highest reported for such arylamine based push-pull derivatives, ${ }^{25,}, 37,38$ reveled a better balanced charge carrier mobility with $\mathrm{C}_{60}$ that might contribute to the impressive fill-factors measured in the corresponding OSCs.

Conclusion: Two push-pull derivatives based on the $N, N$-bis(4-biphenylyl)aniline donor connected to a DCV acceptor by mono- and bithienyl $\pi$-conjugated spacers have been 
synthesized in two steps from commercially available materials. Optical and electrochemical data show that the extension of the spacer leads to a moderate decrease of the oxidation potential and to a small bathochromic shift of the absorption maximum. The characterization of PHJ cells fabricated by thermal evaporation has revealed very high FF values consistent with the high hole mobilities measured for the donor materials. These preliminary results thus provide a strong incitement to continue to investigate structure-properties relationships on active OPV materials derived from small TAAbased molecules.

\section{Materials and Methods}

General information: All reagents and chemicals from commercial sources were used without further purification unless specified. $\mathrm{Pd}_{2}(\mathrm{dba})_{3}$ was repurified from commercial available sources as describe by Ananikov et al. ${ }^{39} \mathrm{KF}$ was powdered and dried overnight in vacuum and at $60{ }^{\circ} \mathrm{C}$. Solvents were dried and purified using standard techniques. Microwave assisted reactions were performed in the cavity of a Biotage Initiator+ system in sealed reactors. Flash chromatography was performed with analytical-grade solvents using ALDRICH silica gel (technical grade, pore size $60 \AA$, 230-400 mesh particle size). Flexible plates ALUGRAM Xtra SIL G UV254 from MACHEREY-NAGEL were used for TLC. Compounds were detected by UV irradiation (BIOBLOCK SCIENTIFIC). NMR spectra were recorded with a BRUKER AVANCE III $300\left({ }^{1} \mathrm{H}, 300 \mathrm{MHz}\right.$ and ${ }^{13} \mathrm{C}$, $75 \mathrm{MHz}$ ). Chemical shifts are given in ppm relative to TMS and coupling constants $\mathrm{J}$ in Hz. UV-vis spectra was recorded with a PERKIN ELMER 950 spectrometer. High resolution mass spectrometry (HRMS) was performed with a JEOL JMS-700 B/E. Cyclic voltammetry was performed using a BIOLOGIC SP-150 potentiostat with positive feedback compensation in $0.10 \mathrm{M} \mathrm{Bu}_{4} \mathrm{NPF}_{6} / \mathrm{CH}_{2} \mathrm{Cl}_{2}$ (HPLC grade). Experiments were carried out in a one-compartment cell equipped with a platinum working electrode ( $2 \mathrm{~mm}$ of diameter) and a platinum wire counter electrode. A silver wire immersed in $0.10 \mathrm{M}$ $\mathrm{Bu}_{4} \mathrm{NPF}_{6} / \mathrm{CH}_{2} \mathrm{Cl}_{2}$ was used as pseudo-reference electrode and checked against the ferrocene/ferrocenium couple $\left(\mathrm{Fc} / \mathrm{FC}^{+}\right)$before and after each experiment. The potentials were then expressed $v s \mathrm{Fc} / \mathrm{Fc}^{+}$. Photoelectron spectroscopy in air (PESA) measurements were recorded using a Riken Keiki PESA spectrometer (Model AC-2) with power settings of $20 \mathrm{nW}$. Final compounds were purified on a JAI recycling HPLC equipped with 2 and $2.5 \mathrm{H}$ columns mounted in serie. 
Synthesis: $\quad$ 5-(4-(di([1,1'-biphenyl]-4-yl)amino)phenyl)thiophene-2-carbaldehyde

(BPA-T-A). A round-button Schlenk flask was charged with $N$-([1,1'-biphenyl]-4-yl)- $N$ (4-bromophenyl)-[1,1'-biphenyl]-4-amine (1) (300 mg, mmol), (5-formylthiophen-2yl)boronic acid (3) (147 mg, $0.94 \mathrm{mmol}), \mathrm{KF}$ (120 mg, $2.08 \mathrm{mmol})$ and $\mathrm{Pd}_{2}\left(\mathrm{dba}_{3}\right.$ (11 mg, $0.01 \mathrm{mmol}$ ). After purging by three argon-vacuum cycles, distilled THF (15 mL) was added followed by $\mathrm{Pt}-(\mathrm{Bu})_{3} 1 \mathrm{M}$ in toluene $(25 \mu \mathrm{L}, 0.02 \mathrm{mmol})$ and the reaction was stirred for $24 \mathrm{~h}$ at room temperature. After filtration of the crude over a path of silica gel, the solvent was removed and the crude purified by column chromatography (eluent: dichloromethane). The obtained yellow compound was precipitated in hexane and filtrated affording the desired product as a yellow powder (277 mg, 86\% yield). ${ }^{1} \mathbf{H}$-NMR (300 MHz, $\left.\mathrm{CDCl}_{3}\right): \delta 9.87$ (s, 1H), 7.72 (d, $\left.J=3.9 \mathrm{~Hz}, 1 \mathrm{H}\right), 7.64-7.51$ (m, 10H), 7.46 (t, $J=7.5 \mathrm{~Hz}, 4 \mathrm{H}), 7.40-7.31$ (m, 3H), 7.25 (d, $J=8.5 \mathrm{~Hz}, 4 \mathrm{H}), 7.19$ (d, $J=8.7 \mathrm{~Hz}, 2 \mathrm{H})$. ${ }^{13}$ C-NMR (75 MHz, $\left.\mathrm{CDCl}_{3}\right): \delta$ 182.7, 154.5, 148.9, 146.2, 141.5, 140.5, 137.9, 136.7, 128.9, 128.2, 127.5, 127.2, 126.9, 126.7, 125.3, 123.1, 123.1. HRMS (FAB+): calculated for $\mathrm{C}_{35} \mathrm{H}_{25} \mathrm{NOS}$ 507.1651, found 507.1662.

\section{5'-(4-(di([1,1'-biphenyl]-4-yl)amino)phenyl)-[2,2'-bithiophene]-5-carbaldehyde}

(BPA-BT-A). To a mixture of pinacol 2 (600 mg, $1.15 \mathrm{mmol}$ ), 5'-bromo-[2,2'bithiophene]-5-carbaldehyde (4) (209 mg, $0.76 \mathrm{mmol}$ ), $\mathrm{Pd}_{2}(\mathrm{dba})_{3}$ (70 mg, $0.08 \mathrm{mmol}$ ) and SPhos (313 mg, $0.76 \mathrm{mmol}$ ) in a microwave tube, tetrahydrofuran (9 mL) and 2M $\mathrm{K}_{2} \mathrm{CO}_{3}$ aqueous solution ( $3 \mathrm{~mL}$ ) were added. The reaction was performed by using a microwave reactor at $70{ }^{\circ} \mathrm{C}$. After $3 \mathrm{~h}$, the reaction was stopped and the mixture was extracted by dichloromethane. The combined organic phases were successively washed with water and brine. Then the solution was dried over $\mathrm{MgSO}_{4}$ and concentrated under reduced pressure. The residue was purified by column chromatography (eluent: dichloromethane) to get the product as an orange solid (400 mg, 89\% yield). ${ }^{1} \mathbf{H}-\mathbf{N M R}$ (300 MHz, $\mathrm{CDCl}_{3}$ ): $\delta 9.86$ (s, 1H), 7.66 (d, $\left.J=4.0 \mathrm{~Hz}, 1 \mathrm{H}\right), 7.61$ (d, $\left.J=7.1 \mathrm{~Hz}, 4 \mathrm{H}\right), 7.58$ - 7.42 (m, 10H), 7.36 (d, $J=7.2 \mathrm{~Hz}, 2 \mathrm{H}), 7.33$ (d, $J=3.8 \mathrm{~Hz}, 1 \mathrm{H}), 7.26-7.22$ (m, 5H), 7.22 - 7.15 (m, 3H). ${ }^{13} \mathrm{C}-\mathrm{NMR}\left(75 \mathrm{MHz}, \mathrm{CDCl}_{3}\right): \delta$ 182.5, 147.8, 147.5, 146.5, 146.2, 141.4, 140.5, 137.6, 136.3, 134.3, 128.9, 128.1, 127.7, 127.4, 127.2, 126.8, 124.9, 123.9, 123.8, 123.5. HRMS (EI+): calculated for $\mathrm{C}_{39} \mathrm{H}_{27} \mathrm{NOS}_{2}$ 589.1529, found 589.1529.

General procedure for Knoevenagel condensation reaction: To a solution of aldehyde $(0.10 \mathrm{mmol})$ and malononitrile $(0.15 \mathrm{mmol})$ in chloroform $(40 \mathrm{~mL})$ were added three drops of triethylamine. The reaction was monitored by thin layer chromatography until consumption of the starting material, then the solvent was evaporated in vacuo and the 
resulting crude purified by column chromatography and injected in a recycling sizeexclusion HPLC.

\section{2-((5-(4-(di([1,1'-biphenyl]-4-yl)amino)phenyl)thiophen-2-}

yl)methylene)malononitrile (BPA-T-DCV). Following the general procedure over BPA-T-A, the final compound was obtained as a red powder after recrystallization from dichloromethane/methanol, to reach a high degree of purity (64\% yield). ${ }^{1} \mathbf{H}-\mathbf{N M R}$ (300 MHz, $\left.\mathrm{CDCl}_{3}\right): \delta 7.75$ (s, 1H), $7.69(\mathrm{~d}, J=4.1 \mathrm{~Hz}, 1 \mathrm{H}), 7.65-7.53(\mathrm{~m}, 10 \mathrm{H}), 7.45$ (t, $J=$ $7.6 \mathrm{~Hz}, 4 \mathrm{H}), 7.38-7.31$ (m, 3H), 7.25 (d, $J=8.4 \mathrm{~Hz}, 4 \mathrm{H}), 7.16$ (d, $J=8.7 \mathrm{~Hz}, 2 \mathrm{H}) .{ }^{13} \mathrm{C}-$ NMR (75 MHz, $\left.\mathrm{CDCl}_{3}\right): \delta 150.1,149.8,148.2,147.9,146.4,140.6,140.4,136.5,133.4$, 133.3, 128.9, 128.7, 128.2, 127.2, 127.2, 126.9, 126.9, 125.1, 124.3, 123.8, 123.6, 114.5, 113.7, 75.7. HRMS (FAB+): calculated for $\mathrm{C}_{38} \mathrm{H}_{25} \mathrm{~N}_{3} \mathrm{~S} 555.1764$, found 555.1765

\section{2-((5'-(4-(di([1,1'-biphenyl]-4-yl)amino)phenyl)-[2,2'-bithiophen]-5-}

yl)methylene)malononitrile (BPA-BT-DCV). Following the general procedure over BPA-BT-A, the final compound was obtained as a violet powder after recrystallization from dichloromethane/methanol, to reach a high degree of purity (30\% yield). ${ }^{1} \mathbf{H}-\mathbf{N M R}$ (300 MHz, $\left.\mathrm{CDCl}_{3}\right): \delta 7.74$ (s, 1H), $7.65-7.58$ (m, 5H), $7.58-7.49$ (m, 6H), 7.46 (d, $J=$ $7.2 \mathrm{~Hz}, 4 \mathrm{H}$ ), 7.41 (d, $J=3.9 \mathrm{~Hz}, 1 \mathrm{H}$ ), 7.34 (tt, $J=7.3,1.3 \mathrm{~Hz}, 2 \mathrm{H}), 7.27$ (d, $J=4.2 \mathrm{~Hz}$, 1H), 7.26 - 7.22 (m, 5H), 7.18 (d, $J=8.7 \mathrm{~Hz}, 2 \mathrm{H}) .{ }^{13} \mathrm{C}-\mathrm{NMR}$ (75 MHz, CDCl3): $\delta 150.1$, 149.8, 148.2, 147.9, 146.4, 140.6, 140.4, 136.5, 133.4, 133.3, 128.9, 128.6, 128.2, 127.2, 127.2, 126.9, 126.9, 125.1, 124.3, 123.8, 123.6, 114.5, 113.7, 75.7. HRMS (EI+): calculated for $\mathrm{C}_{42} \mathrm{H}_{27} \mathrm{~N}_{3} \mathrm{~S}_{2}$ 637.1641, found 637.1639.

Device fabrication: Thin films and planar-heterojunction solar cell devices were prepared by thermal vapour deposition onto room temperature substrates in an ultra-high vacuum chamber with a base pressure of $10^{-7}$ mbar. Thin films for absorption and emission measurements were prepared on quartz substrates; solar cells on tin-doped indium oxide (ITO) coated glass (Thin Film Devices, USA, sheet resistance of $30 \Omega \mathrm{sq}^{-1}$ ). Layer thicknesses were determined during evaporation by using quartz crystal monitors calibrated for the respective material. The thin films prepared for absorption and emission measurements were approximately $30 \mathrm{~nm}$ thick. Solar cells were prepared layer by layer with-out breaking the vacuum as follows: ITO; $6 \mathrm{~nm}$ BPA-T-DCV or BPA-BT-DCV; 10 nm BPAPF; 45 nm BPAPF doped with NDP9 (purchased from Novaled AG Germany, $10 \mathrm{wt} \%) ; 1$ nm NDP9; 100 nm Al.

$J-V$ and $E Q E$ measurements were carried out in a solvent-free $\mathrm{N}_{2}$ filled glovebox $\left(\mathrm{O}_{2}\right.$ and $\mathrm{H}_{2} \mathrm{O}$ levels <1ppm). $J-V$ characteristics were measured using a source-measure unit 
(Keithley SMU 2400) and an AM 1.5G sun simulator (KHS Technical Lighting SC1200). The intensity was monitored with a silicon photodiode (Hamamatsu S1337), which was calibrated at Fraunhofer ISE. The mismatch between the spectrum of the sun simulator and the solar AM 1.5G spectrum was taken into account for the calculation of current density. Aperture masks $\left(2.76 \mathrm{~mm}^{2}\right)$ were used to obtain well-defined active solar cell areas.

SCLC measurements: Hole mobilities have been determined by the space-charge current limited method using the Mott-Gurney law on hole-only devices ITO/PEDOT:PSS/donor/gold using spun-cast films of donors BPA-T-DCV and BPABT-DCV of 120-150 nm thickness.

Computational methods: The gas-phase ground-state equilibrium geometry of representative molecules was obtained by performing DFT optimization at energy functional B3LYP using the 6-311G(d) split-valence Pople's basis set for all the atomic species. Polarizable continuum model (PCM) was resorted to take into account the electrostatic effects of the polarizable environment using a dielectric constant. Ultimately, as for the optical properties, TD-DFT calculations were carried out. All DFT and TDDFT simulations were performed using the Gaussian 09 package suite.

Acknowledgments: Authors thank the MATRIX SFR of the University of Angers. J.M.A.C. and P.S.M. thanks the European Union's Horizon 2020 research and innovation program under Marie Sklodowska Curie Grant agreement No.722651 (SEPOMO).

\section{References:}

1. P. Agarwala and D. Kabra, Journal of Materials Chemistry A, 2017, 5, 1348-1373.

2. C. Cabanetos, P. Blanchard and J. Roncali, The Chemical Record, 2019, 19, 1123-1130.

3. C. H. Teh, R. Daik, E. L. Lim, C. C. Yap, M. A. Ibrahim, N. A. Ludin, K. Sopian and M. A. Mat Teridi, Journal of Materials Chemistry A, 2016, 4, 15788-15822.

4. J. Roncali, P. Leriche and P. Blanchard, Advanced Materials, 2014, 26, 3821-3838.

5. P. Blanchard, C. Malacrida, C. Cabanetos, J. Roncali and S. Ludwigs, Polymer International, 68, 589-616.

6. Y. Cui, H. Yao, J. Zhang, K. Xian, T. Zhang, L. Hong, Y. Wang, Y. Xu, K. Ma, C. An, C. He, Z. Wei, F. Gao and J. Hou, Advanced Materials, 2020, DOI: 10.1002/adma.201908205, 1908205.

7. W. Xu, B. Peng, J. Chen, M. Liang and F. Cai, The Journal of Physical Chemistry C, 2008, 112, 874-880.

8. R. Zhou, Z. Jiang, C. Yang, J. Yu, J. Feng, M. A. Adil, D. Deng, W. Zou, J. Zhang, K. Lu, W. Ma, F. Gao and Z. Wei, Nature Communications, 2019, 10, 5393.

9. Y. Lin, Y. Li and X. Zhan, Chemical Society Reviews, 2012, 41, 4245-4272. 
10. A. Wadsworth, M. Moser, A. Marks, M. S. Little, N. Gasparini, C. J. Brabec, D. Baran and I. McCulloch, Chemical Society Reviews, 2019, 48, 1596-1625.

11. A. Labrunie, P. Josse, S. Dabos-Seignon, P. Blanchard and C. Cabanetos, Sustainable Energy \& Fuels, 2017, 1, 1921-1927.

12. H.-S. Shim, C.-K. Moon, J. Kim, C.-K. Wang, B. Sim, F. Lin, K.-T. Wong, Y. Seo and J.-J. Kim, ACS Applied Materials \& Interfaces, 2016, 8, 1214-1219.

13. X. Che, X. Xiao, J. D. Zimmerman, D. Fan and S. R. Forrest, Advanced Energy Materials, 2014, 4, 1400568.

14. S. Roquet, A. Cravino, P. Leriche, O. Alévêque, P. Frère and J. Roncali, Journal of the American Chemical Society, 2006, 128, 3459-3466.

15. A. Cravino, P. Leriche, O. Alévêque, S. Roquet and J. Roncali, Advanced Materials, 2006, 18, 3033-3037.

16. A. Leliège, P. Blanchard, T. Rousseau and J. Roncali, Organic Letters, 2011, 13, 30983101.

17. O. Vybornyi, Y. Jiang, F. Baert, D. Demeter, J. Roncali, P. Blanchard and C. Cabanetos, Dyes and Pigments, 2015, 115, 17-22.

18. A. Leliège, C.-H. L. Régent, M. Allain, P. Blanchard and J. Roncali, Chemical Communications, 2012, 48, 8907-8909.

19. A. Labrunie, Y. Jiang, F. Baert, A. Leliège, J. Roncali, C. Cabanetos and P. Blanchard, RSC Advances, 2015, 5, 102550-102554.

20. F. Baert, C. Cabanetos, M. Allain, V. Silvestre, P. Leriche and P. Blanchard, Organic Letters, 2016, 18, 1582-1585.

21. R. Po and J. Roncali, Journal of Materials Chemistry C, 2016, 4, 3677-3685.

22. Y. Jiang, D. Gindre, M. Allain, P. Liu, C. Cabanetos and J. Roncali, Advanced Materials, 2015, 27, 4285-4289.

23. Y. Jiang, C. Cabanetos, S. Jungsuttiwong, D. Alberga, C. Adamo and J. Roncali, ChemistrySelect, 2017, 2, 6296-6303.

24. S. Mohamed, D. Demeter, J.-A. Laffitte, P. Blanchard and J. Roncali, Scientific Reports, 2015, 5, 9031.

25. Y. Jiang, C. Cabanetos, M. Allain, P. Liu and J. Roncali, Journal of Materials Chemistry C, 2015, 3, 5145-5151.

26. H. Inada, K. Ohnishi, S. Nomura, A. Higuchi, H. Nakano and Y. Shirota, Journal of Materials Chemistry, 1994, 4, 171-177.

27. Y. Shirota and H. Kageyama, Chemical Reviews, 2007, 107, 953-1010.

28. A. Higuchi, K. Ohnishi, S. Nomura, H. Inada and Y. Shirota, Journal of Materials Chemistry, 1992, 2, 1109-1110.

29. A. F. Littke, C. Dai and G. C. Fu, Journal of the American Chemical Society, 2000, 122, 4020-4028.

30. R. Martin and S. L. Buchwald, Accounts of Chemical Research, 2008, 41, 1461-1473.

31. J. W. Choi, C.-H. Kim, J. Pison, A. Oyedele, D. Tondelier, A. Leliège, E. Kirchner, P. Blanchard, J. Roncali and B. Geffroy, RSC Advances, 2014, 4, 5236-5242.

32. H. Kageyama, H. Ohishi, M. Tanaka, Y. Ohmori and Y. Shirota, Advanced Functional Materials, 2009, 19, 3948-3955.

33. Y. Lin, L. Ma, Y. Li, Y. Liu, D. Zhu and X. Zhan, Advanced Energy Materials, 2014, 4, 1300626.

34. A. Wadsworth, H. Bristow, Z. Hamid, M. Babics, N. Gasparini, C. W. Boyle, W. Zhang, Y. Dong, K. J. Thorley, M. Neophytou, R. S. Ashraf, J. R. Durrant, D. Baran and I. McCulloch, Advanced Functional Materials, 2019, 29, 1808429.

35. W. Gao, Q. An, M. Hao, R. Sun, J. Yuan, F. Zhang, W. Ma, J. Min and C. Yang, Advanced Functional Materials, 2020, 30, 1908336.

36. J. Gao, j. Ge, R. Peng, C. Liu, L. Cao, D. Zhang, F. Billy, L. Hong, E. Zhou and Z. Ge, Journal of Materials Chemistry A, 2020, DOI: 10.1039/D0TA01893G. 
37. H. M. Ko, H. Choi, S. Paek, K. Kim, K. Song, J. K. Lee and J. Ko, Journal of Materials Chemistry, 2011, 21, 7248-7253.

38. Y. Jiang, M. Allain, D. Gindre, S. Dabos-Seignon, P. Blanchard, C. Cabanetos and J. Roncali, Scientific Reports, 2017, 7, 8317.

39. S. S. Zalesskiy and V. P. Ananikov, Organometallics, 2012, 31, 2302-2309. 